Revista

A Cor

das Letras

\title{
O professor de línguas, o PNLD, o livro didático de línguas e outros materiais didáticos
}

\section{The language teacher, PNLD, the language coursebook and other teaching materials}

\author{
Renato Caixeta da Silva* \\ Centro Federal de Educação Tecnológica de Minas Gerais \\ Belo Horizonte, Minas Gerais, Brasil
}

\begin{abstract}
Resumo: Este artigo tem o Programa Nacional do Livro Didático (PNLD) como pano de fundo para as discussões apresentadas. Objetiva-se mostrar as situações e as demandas que o professor de línguas tem enfrentado atualmente e confrontá-las com as relações entre o professor e o livro didático e outros materiais de ensino no seu cotidiano profissional. Para atingir esse objetivo, recorre-se a autores que têm refletido sobre o docente de línguas e a profissão docente, a referências aos docentes em textos produzidos no próprio PNLD (resoluções e Guia do Livro Didático) e a pesquisas realizadas nos últimos anos pelo Grupo de Pesquisa em Materiais e Recursos Didáticos do CEFET-MG. Assumindo uma postura crítica, argumenta-se sobre a necessidade de o PNLD e outras políticas de provimento de materiais para ensino promoverem novas iniciativas de apoio ao docente em prol de uma educação mais libertadora e menos opressiva.
\end{abstract}

Palavras-chave: Livros didáticos. Ensino de Língua. Professor de Língua. PNLD.

\begin{abstract}
This article has the Brazilian Textbook National Programme (PNLD) as a background for the presented discussions. It is the aim to show the language teacher's recent situations and demands and to compare them to the teacher's relationship with the textbook and other language teaching materials in his everyday professional context. In order to accomplish the aim, we refer to authors who have reflected upon the teacher and the teaching profession, to references about teachers in texts produced within the programme, and researches conducted at the Research Group on Teaching Materials and Resources from CEFET-MG. Assuming a critical viewpoint, it is argued about the necessity the governamental programmes of teaching material providence to promote new initiatives to really support teachers in order to promote a freer and less opressive education.
\end{abstract}

Keywords: Coursebooks. Language teaching. Language teacher. PNLD

\section{INTRODUÇÃO}

Diferentes agentes sociais contribuem para a chegada do livro didático de línguas (materna e estrangeira) ao aluno brasileiro via Programa Nacional do Livro Didático (PNLD). Os autores concebem obras encomendadas por editoras a que estão ligados ou por iniciativa própria, um trabalho que demanda pesquisa e tempo para se delinear

* Professor Titular de Língua Inglesa do Departamento de Linguagem e Tecnologia (DELTEC) Centro Federal de Educação Tecnológica de Minas Gerais (CEFET-MG), Campus I, Belo Horizonte, MG. Líder do Grupo de Pesquisas em Materiais e Recursos Didáticos do CEFETMG.Email: rencaixe@yahoo.com.br. 
objetivo de uma coleção didática, concepção de língua e de aprendizagem, conteúdo e atividades coerentes com a proposta e com o público alvo a ser atingido. Também há decisões sobre gradação de conteúdo e de atividades. Os editores também têm forte atuação na produção do livro didático, influenciando e determinando a sua organização, seu projeto gráfico-editorial, os objetos de ensino, mas com uma visão também voltada para o mercado (TEIXEIRA, 2012), incluindo as normas e os critérios de avaliação que regem o PNLD. Em suma, autor e editor exercem a autoria e devem estar atentos a questões administrativas e acadêmicas que determinam as políticas públicas de ensino no Brasil, para que o produto de suas ações, o livro didático, tenha sucesso, sendo aprovado e incorporado ao programa, o que permitirá que ele seja adotado em escolas e consequentemente vendido.

Mas para que isso aconteça, em se tratando de PNLD, há ainda o processo de avaliação, seguindo os critérios dispostos no edital que rege cada edição do programa. Conforme descrito no sítio eletrônico do Programa ${ }^{1}$, parte dessa avaliação refere-se às exigências técnicas e físicas previstas no edital e é feita pelo Instituto de Pesquisas Tecnológicas do Estado de São Paulo (IPT). Os livros aprovados nessa primeira triagem são avaliados pedagogicamente pela Secretaria de Educação Básica (SEB/MEC), a qual escolhe os especialistas que analisam as obras de acordo com os critérios constantes no edital. A partir dessas avaliações, resenhas dos livros aprovados são redigidas para comporem o guia de livros didáticos. Assim, tem-se o avaliador como mais um agente responsável pela chegada do livro didático ao aluno, sendo que é no processo de avaliação que se tem uma definição de obras didáticas disponíveis para escolha por parte do professor.

No Brasil, como o PNLD é um programa nacional e bem abrangente, incluído na esfera governamental federal, o Estado é também um agente responsável pela chegada do livro didático ao aluno. É o governo que, por meio dos editais, determina critérios para aprovação de obras didáticas e, com isso, determina a produção, a qualidade, estipula quais livros são considerados pertinentes ao ensino brasileiro e movimenta mercado com a compra. Ter um livro aprovado no PNLD é de grande valor para editoras e autores. Além de o livro ser considerado adequado para ser adotado em escolas brasileiras, portanto possível de ser comprado, essa chancela serve de base para a aceitação dos mesmos títulos em escolas privadas, as quais não são incluídas no programa.

Mas é o professor o agente que está mais próximo do aluno, que conhece sua realidade de ensino e de aprendizagem e que deve, conforme preconizado pelo programa, analisar e escolher os livros que serão utilizados em sua escola. Em última instância, é do professor a decisão de escolha de um ou outro livro didático, decisão essa a ser informada aos gestores do PNLD para guiar a compra e distribuição das obras. O foco do presente artigo, portanto, é esse agente usuário, não produtor do livro didático, suas atividades na atualidade e sua relação com o livro didático, o PNLD e outros materiais de ensino. 
Os objetivos que norteiam este trabalho são: mostrar o que se demanda do professor de línguas na atualidade e com o PNLD e confrontar essa demanda com as relações que o próprio professor tem com o livro didático e outros materiais didáticos no seu cotidiano profissional. Para tanto, recorre-se a autores que têm refletido sobre o docente de línguas e a profissão docente, a referências aos docentes em textos produzidos no próprio PNLD (resoluções e Guia do Livro Didático) e a trabalhos investigativos realizados junto ao Grupo de Pesquisa em Materiais e Recursos Didáticos do CEFETMG. Por fim, numa perspectiva crítica, argumenta-se sobre a necessidade de o PNLD e outras políticas de provimento de materiais para ensino serem instigadores de novas iniciativas de verdadeiro apoio ao docente.

\section{O PROFESSOR DE LÍNGUAS}

Celani (2006) defende que a atividade docente não é uma simples ocupação, embora assim seja percebida e considerada por muitos. Os argumentos da autora são a especialização requerida para se exercer a atividade docente, a remuneração dela decorrente, a exigência de uma formação acadêmica, seu caráter político por estabelecer pontes com a sociedade em que se insere e o compromisso do profissional para com seu público - os alunos, a instituição onde trabalha e ainda consigo mesmo, investindo em sua carreira. Nesse sentido, Celani também defende que o professor de línguas não pode ser controlado por outros, mas deve ser sujeito agente de seu fazer profissional.

Esse docente, ao mesmo tempo, está inserido no meio social e cultural que evolui ao longo de seu tempo de serviço, sendo influenciado pelas escolas por que passa em sua formação escolar e profissional, pelas reformas educacionais e pelos contextos políticos (MARCELO, 2010). Esses, por sua vez, trarão mudanças e novas maneiras de encarar a realidade de trabalho, interferirão na motivação para aprendizagens novas, nos valores, no conhecimento específico a que o professor se dedica, experiências novas e antigas, enfim, na sua identidade profissional. Isso encontra ressonância nas ideias de Bohn (2006), de que, na contemporaneidade, não mais existem respostas prontas aos desafios e que o professor de línguas vive mais na incerteza do que na certeza, precisando assumir a condição de aprendizagem contínua no exercício da profissão. Para dar conta dessa situação, o professor necessita de formação, não de treinamento, pois que se faz necessária a reflexão sobre os acontecimentos, a preparação para novas situações com embasamentos teóricos pertinentes, não se limitando ao presente, ao aqui e agora (LEFFA, 2006).

Entretanto, atualmente, percebe-se que o professor muitas vezes não se encontra bem preparado nos cursos de graduação (LEFFA, 2007) para tantos desafios: novas maneiras de ensinar, novos comportamentos de alunos, novas tecnologias, novas visões sobre o que e como ensinar e novas políticas educacionais. As condições de trabalho docente muitas vezes são caracterizadas pela falta de uma formação continuada, por episódios de violência, pela inapetência de professores, desmotivação de alunos para com a escola e o saber ali promovido. Não raro, encontramos professores que, além de exercerem o ofício de ensinar, devem também assumir outras funções como psicólogos e 
assistentes sociais (CITELLI, 2012; MARCELO, 2010) em seus contextos na tentativa de ajudar a se amenizar os problemas enfrentados em vários contextos públicos ou privados. Não é comum, no Brasil, a presença desses outros profissionais nas escolas, o que parece ser cada vez mais necessário. Muitas vezes, também, o professor de línguas não é usuário da língua que ensina, pois ele sabe e ensina sobre a língua, mas pouco, ou quase nunca, tem oportunidades de efetivamente usar aquela língua, seja materna seja estrangeira, em produção de textos escritos ou orais (CONSOLO, 2010). Contribuem para esse fato as diversas tarefas extraclasse inerentes à profissão, nem sempre remuneradas, a necessidade de se assumirem muitas horas/aula em diferentes estabelecimentos de ensino para complementação salarial e ainda o pouco reconhecimento e baixa remuneração decorrentes da realização de um curso de pós-graduação ou de atualização.

A mídia vem, cotidianamente, representando o professor em geral com base em estereótipos, com acusações de incompetência e inapetência, como vítima de violência e constrangimentos e, ao mesmo tempo, por meio de exemplos de empenho, como promotor da boa educação, uma pessoa que tem determinação e inovação, responsável pela qualidade do ensino e da educação, detentor de conhecimento e condutor da sala de aula, mantenedor da ordem (CITELLI, 2012). Essas representações mostram e determinam, consequentemente, a visão de professor presente no cotidiano da sociedade, pois, como afirmam Jodelet (1995) e Moscovici (2003), as representações determinam práticas sociais. Em outras palavras, é assim que o professor é visto na sociedade brasileira: ora negativamente como uma profissão desrespeitada, ora como o promotor e responsável pela educação de crianças e jovens. Em suma, reconhecido, mas desvalorizado.

Marcelo (2010) defende que as expectativas do profissional, as realidades em que ele se insere, os estereótipos construídos sobre ele e suas condições de trabalho, tudo isso contribui para a construção de uma autoestima e a própria imagem social. Se ser professor no início do século XX era algo respeitável e de prestígio, com diz esse autor, no século XXI percebem-se riscos no trabalho docente, sobrecarga de tarefas, baixo reconhecimento, desprestígio e a transmissão, na mídia, de uma imagem negativa da realidade educacional. Além disso, como exposto por Leffa (2007), a formação universitária também tem ajudado pouco na mudança dessa realidade, e parece estar distante uma prática docente crítico-reflexiva com aceitação de diferenças, com aceitação de conflitos e instabilidades, habilidade com grande volume de informações dos meios de comunicação e de redes sociais e enfrentamento consciente e profissional dos desafios $(\text { ALVAREZ, 2013) })^{2}$.

\section{O PROFESSOR NO PNLD}

O PNLD é o maior programa governamental de distribuição de livros didáticos, que tem se caracterizado como de Estado por ultrapassar governos de diferentes

2 ALVAREZ, Maria Luíza Ortiz. Entrevista com Maria Luíza Ortiz Alvarez, por Denise Scheyerl e Sávio Siqueira, In.: SCHEYERL, D. e SIQUEIRA, S. (2013). 
tendências políticas. Cassiano (2013) mostra sua longa história e as muitas mudanças significativas por que passou. Dessas, uma das mais significativas foi a criação da avaliação das obras didáticas, o que procura conferir uma possibilidade de garantia de qualidade, atualização e respeito à diversidade sociocultural nas obras adotadas nas escolas. Embora criticada por alguns (SOUZA, 1999, por exemplo), essa avaliação, que também tem sofrido mudanças e aperfeiçoamentos ao longo do tempo, é referência para a escola pública, na medida em que apresenta livros possíveis de serem escolhidos por estarem de acordo com o que se espera para a Educação Nacional atualmente; também para a escola particular, pois um livro aprovado numa avaliação do PNLD é entendido como de qualidade e sua adoção pode ser menos arriscada. Essa avaliação também serve ao meio editorial, pois esse tem um retorno dos seus parâmetros de produção.

A abrangência nacional do PNLD e as grandes cifras nele envolvidas contrastam com o desconhecimento de muitos docentes e gestores a respeito do funcionamento do programa. Algumas pesquisas com professores de línguas têm mostrado que os docentes ainda não têm clareza da abrangência do programa, do seu direito ao livro de qualidade, de o que determina o recebimento de um livro escolhido ou não escolhido. Será mostrado mais adiante que algumas investigações têm mostrado as reclamações de professores sobre tal escolha. Há escolas onde os docentes mostram-se desmotivados a participarem das reuniões para a seleção de livros, e ela ainda parece acontecer de maneira intuitiva, desorganizada, ou muitas vezes estão envolvidos outros interesses que não pedagógicos (OLIVEIRA, 2015; SILVA E PEREIRA, 2015).

A Resolução 42 de 28 de agosto de 2012 (Alterada pelas Resoluções no 22, de 7 de junho de 2013, e $\mathrm{n}^{\circ} .44$ de 13 de novembro de 2013) estipula claramente o papel do professor e da escola na seleção e escolha de livros pelo PNLD. Segundo o texto do documento,

IV - às escolas participantes compete: (...)

b) viabilizar a escolha dos livros didáticos com a efetiva participação de seu corpo docente e dirigente, registrando os títulos escolhidos (em primeira e segunda opção, de editoras diferentes e as demais informações requeridas no sistema disponibilizado pelo FNDE na internet, conforme as orientações especificadas; $\mathrm{V}$ - aos professores compete:

a) participar do processo de escolha dos títulos para a respectiva escola, dentre aqueles relacionados no guia de livros didáticos disponibilizado pelo FNDE;

b) observar, no que se refere ao processo de escolha, a proposta pedagógica e a realidade específica da sua escola; (grifos do autor)

As Orientações para o registro da escolha do PNLD 2015 (Ensino Médio) ressaltam ainda a autonomia do professor, pois a reunião para seleção tem caráter decisivo, deve ser registrada e a decisão arquivada. Também há uma proibição de participação de representantes de editoras no processo de escolha das escolas e de recebimento de vantagens pela escola. Infelizmente, ainda não se pode dizer que a existência do PNLD por si só tem promovido a viabilização do processo de escolha de maneira satisfatória para os docentes, a participação conjunta, a observância de critérios, da proposta pedagógica e da realidade escolar. A pesquisa de Oliveira (2015), sobre os 
discursos de docentes a respeito do processo de escolha de livros didáticos de História, revela que os docentes reconhecem a importância do momento de avaliação e escolha do livro, reconhecem a importância do programa, mas que ainda é preciso melhorá-lo. Segundo os participantes dessa pesquisa, muitos docentes não participam por não serem do quadro efetivo das escolas públicas, por haver rotatividade anual no quadro de professores contratados, não se interessam, ou não há momentos específicos para isso.

Mas o professor de línguas não é apenas um agente da seleção e da escolha das obras para seu contexto de trabalho. Durante o uso do livro didático escolhido ou recebido, ele tem várias tarefas. Para exemplificar, recorro às seções "Em sala de aula" contidas nas resenhas do Guia do Livro Didático de Língua Estrangeira Moderna para Ensino Médio 2015 (BRASIL, 2015). Nessas seções, diz-se que, ao usar o livro didático, o professor deve

- ampliar contato do aluno com outras possibilidades,

- desenvolver estratégias que levem os alunos a uma preparação (melhor),

- propor projetos, outras tarefas, complementações,

- suprir conteúdos, atividades, textos, precisões,

- atentar-se para limitações, aprofundar,

- revisar, e reelaborar atividades e conteúdos.

Conclui-se que do professor é esperado assumir múltiplos papéis. Ele seleciona o livro didático e assim assume o olhar de avaliador, que dentro do seu contexto ele deve, de fato, ter. Mas cabe a ele também assumir o fazer de autores e editores quando supre conteúdos, atividades e textos, quando revisa e reelabora. Usar o livro didático, para o professor, então, não deve, no entender dos próprios avaliadores do PNLD, seguir fielmente a obra adotada, mas estar atento às suas possibilidades e limitações, assumir outras tarefas que não simplesmente cumprir o conteúdo e as atividades propostas no material didático.

\section{O PROFESSOR E O LIVRO DIDÁTICO}

Na pesquisa de Silva (2012) (ver também SILVA, 2016), o livro didático de inglês foi tomado como objeto de investigação a partir de sua importância na sociedade. Procurou-se entender esse material de ensino a partir dos dizeres de pessoas envolvidas na sua produção (autores e editores) e na sua utilização (professores e alunos), isto é, aquelas que lidam com ele no seu cotidiano. Numa perspectiva funcional da linguagem ${ }^{3}$, foram analisados discursos de produtores contidos em anúncios de catálogos, quartas capas e no manual do professor, também entrevistas com professores e questionários com alunos desses docentes. Nessa pesquisa, detectou-se que o livro é objeto de representação social devido à sua importância na sociedade em geral. Para docentes de inglês, em

\footnotetext{
${ }^{3}$ Nesta pesquisa, o referencial teórico utilizado foi a Linguística Sistêmico-Funcional de Michael Halliday.
} 
específico, ele é fonte, agente, facilitador, suporte, organizador, atração, guia, curso, mercadoria e possibilidade.

Com a pesquisa de Silva e Pereira (2014), por meio de questionário respondido por professores de diferentes áreas e disciplinas do currículo do Ensino Médio em uma escola de ensino médio e profissional da rede federal localizada em Belo Horizonte, procurou-se entender a recepção de livros do PNLD pelos docentes que ali atuam. Chegou-se à conclusão de que o livro didático de línguas (português e inglês) é também visto pelos docentes de português como fonte de consulta e proposta de tarefas para casa, fonte de enriquecimento das aulas, acesso a textos e imagens, auxilio no processo, complemento, fonte de pesquisa e leitura, suporte, consulta e fonte de atividades para serem utilizadas com alunos. Para professores de inglês desse contexto, o livro didático é guia para atividades de desenvolvimento de competência comunicativa, ferramenta de exercício de autonomia, suporte para desenvolver produção textual. Essa pesquisa corrobora a pesquisa de Silva (2012) e acrescenta que livros didáticos de outras disciplinas são representados pelos docentes de maneira semelhante como o livro didático de inglês, o que equivale a dizer que esses são os papéis atribuídos aos livros didáticos no contexto escolar:

Fonte - a origem de tudo, aquilo que provê;

Agente - aquele que faz (mostra, apresenta, ensina, traz, facilita, orienta, ...);

Facilitador - aquele que facilita, permite facilitar;

Suporte - a base em que se assenta o ensino;

Organizador - ajuda na organização das aulas;

Atração - o que se deseja para as aulas, motivador;

Guia - o que orienta e direciona;

Curso - determinador do que acontece em sala;

Mercadoria - tem valor comercial, representa algo comprado;

Possibilidade - uma dentre várias escolhas.

(SILVA, 2012; SILVA, 2016)

\section{O PROFESSOR E O LIVRO DIDÁTICO DO PNLD}

Algumas pesquisas recentes têm enfatizado a escolha e a avaliação de livros didáticos por professores, quer de línguas quer de outros componentes curriculares (OLIVEIRA, 2015; SILVA, ASSIS, SANTOS, 2015; ZAMBON, TERRAZAN, 2013). Nesses trabalhos, dentre outros, percebe-se que a escolha de livros didáticos do PNLD nas escolas públicas tem se caracterizado pela falta de tempo hábil, sendo as avaliações feitas pelos professores em separado, em horários de intervalo (15 a 20 minutos do tempo de recreio dos alunos), ocorrendo reuniões finais muito rápidas com todos os docentes para repassarem a escolha para a coordenação pedagógica ou a direção da escola. Nesse processo, o guia do livro didático tem sua importância mas não maior que a consulta ao livro e ao colega (SILVA, 2010; OLIVEIRA, 2015), o que também mostra que professores têm opiniões pré-formadas e dificilmente mudam de um livro para outro com proposta 
mais inovadora ou atualizada. Os trabalhos também denunciam, em alguns contextos, o descaso ou desinteresse nas escolhas, uma vez que a participação do professor em reuniões é para que ele chancele uma escolha feita para a rede não para a escola, silenciando o professor nesse momento próprio do fazer docente. Em alguns lugares, é comum a exclusão de alguns professores em caráter não efetivo nos momentos de discussão e decisão, visto que possivelmente aquele professor não estará na escola no ano seguinte (OLIVEIRA, 2015).

Docentes também têm reclamado, em pesquisas, uma desmotivação para essa participação com a justificativa de nem sempre o livro escolhido chegar à escola. Isso mostra o desconhecimento da dinâmica do programa, pois somente após a avaliação dos livros e indicação pelas escolas é que o MEC negocia a compra, e editoras podem não aceitar a negociação ou ainda não estarem em condições de venderem para o governo por causa de pendências trabalhistas, com a Previdência Social, ou outras.

Quanto à recepção desses livros pelos docentes, a pesquisa de Silva e Pereira (2014) já mencionada mostra que docentes dos diversos componentes curriculares reconhecem que o livro didático atende ao contexto de ensino e aprendizagem daquela instituição, mas esse atendimento é considerado parcial pelos professores. Eles apresentam, majoritariamente em seus discursos, atitudes positivas com relação ao livro adotado e recebido. Alguns professores de línguas (português e inglês) da instituição em que a investigação aconteceu expressam suas atitudes em seus discursos de maneira a enfatizar o valor do livro, sua composição e a reação dos alunos. Seguem excertos de suas avaliações coletadas por escrito.

Essa ênfase na apreciação do livro didático em termos de sua composição, como mostram os dados, corrobora a ideia apresentada de que o livro didático tem papel de fonte de textos, atividades, outros recursos e ao mesmo tempo de suporte: é de lá que vem o que ensinar (conteúdo), o como ensinar (através de quais textos e atividades), e assim é nessa fonte e no que ela provê que o professor baseia seu trabalho pedagógico, seja usando o livro em sala, seja atribuindo a ele um papel de referência para o aluno estudar em casa antes ou depois das aulas (o suporte).

\begin{tabular}{|c|c|c|}
\hline \multirow[t]{3}{*}{ Português } & Prof 1 & $\begin{array}{l}\text { Bom livro didático, boa explanação, muitas sugestões - apreciação }(+) \text { composição } \\
\text { (quantidade e complexidade); gradação. } \\
\text { Atividades pouco objetivas; livro que não se mostra sucinto e objetivo - apreciação } \\
\text { composição }(-) \text { / complexidade; gradação. } \\
\text { Bom conteúdo - apreciação }(+) \text { composição }(+) \text {. }\end{array}$ \\
\hline & Prof. 2 & $\begin{array}{l}\text { Clareza e riqueza do conteúdo, muito rico, linguagem clara e objetiva - apreciação }(+) \\
\text { composição quantidade e complexidade. } \\
\text { Relevante, imagens pertinentes e relevantes ao conteúdo - apreciação }(+) \text { valor } \\
\text { Gosto de fazer apostilas - afeto pelo trabalho além livro. } \\
\text { Percebo que sentem que o livro foi bem usado - engajamento apropriação do } \\
\text { sentimento do aluno para expressar sua percepção. Julgamento de sua } \\
\text { conduta como professora que usa o livro didático, não com relação ao livro } \\
\text { em si. }\end{array}$ \\
\hline & Prof 3 & $\begin{array}{l}\text { O livro deixa desejar. apreciação negativa. } \\
\text { Serve de material de apoio e consulta do aluno (apreciação positiva) } \\
\text { Não considera o livro adequado (apreciação negativa). }\end{array}$ \\
\hline
\end{tabular}




\begin{tabular}{|c|c|c|}
\hline & & $\begin{array}{l}\text { O tal LD não apresenta atrativa relação "custo beneficio". apreciação } \\
\text { negativa. }\end{array}$ \\
\hline & Prof 4 & $\begin{array}{l}\text { Avalio o livro negativamente por não tratar a literatura como arte. apreciação negativa- } \\
\text { composição. } \\
\text { O papel do livro em sala de aula épraticamente nenbum. (apreciação negativa) } \\
\text { Não é adequado por trazer reunidas duas disciplinas que são dadas separadamente. } \\
\text { (apreciação negativa). - composição. }\end{array}$ \\
\hline & Prof 5 & $\begin{array}{l}\text { Não apresenta muita relação com os conteúdos temáticos de Redação - apreciação (-) } \\
\text { quanto ao valor; gradação } \\
\text { Excelente livro - apreciação (+) gradação, valor. } \\
\text { Gosto das autoras - afeto (+) sentimento. } \\
\text { Para redação não bá muito conteúdo - apreciação (-) composição. } \\
\text { Muito pesado (-) - apreciação composição, gradação. } \\
\text { Adequado mais para português que para redação -apreciação }(+) \text { valor - adequação. }\end{array}$ \\
\hline & Prof 6 & $\begin{array}{l}\text { Apreciações relativas à composição principalmente à complexidade - } \\
\text { gradação Despertam curiosidade e gosto - apreciação (+) relativa à reação. } \\
\text { Adequado ao contexto as explicaçôes são claras, exercícios de fácil compreensão, organiza } \\
\text { o conteúdo didático e foca nos conteúdos essenciais de gramática, explicações claras - } \\
\text { apreciação positiva. }\end{array}$ \\
\hline & Prof 7 & $\begin{array}{l}\text { A quantidade de exercícios oferecida em cada unidade é satisfatória e as questões são bem } \\
\text { elaboradas. (apreciação positiva) - composição. } \\
\text { É adequado ao contexto. (apreciação positiva) - valor. } \\
\text { Pode ser consultado facilmente pelos alunos. (apreciação positiva) - composição/ } \\
\text { complexidade. } \\
\text { As explicações são claras e os seus exercícios apresentam enunciados de fácil compreensão. } \\
\text { (apreciação positiva) - composição / complexidade. } \\
\text { O livro não resolve as defasagens dos alunos. (apreciação negativa). }\end{array}$ \\
\hline Inglês & Prof 1 & $\begin{array}{l}\text { Adequado à proposta pedagógica - apreciação }(+) \\
\text { Gradação confusa, falta material de apoio - apreciação (-) composição } \\
\text { complexidade } \\
\text { Assunto não chama atenção de aluno - apreciação (-) reação }\end{array}$ \\
\hline & Prof 2 & $\begin{array}{l}\text { Os alunos gostam de criar mas detestam fazer os exercícios do livro (...) muitos acham que } \\
\text { os temas são muito bobos- apreciação (-) reação; afeto (-) e (+) mas a avaliação } \\
\text { do professor é feita na voz dos alunos - Heteroglossia }\end{array}$ \\
\hline & Prof 3 & $\begin{array}{l}\text { Mais adequado à proposta - apreciação }(+) \text { valor adequação } \\
\text { Ferramenta - instrumento para aluno - apreciação }(+) \text { valor - usa a voz do aluno }\end{array}$ \\
\hline & Prof 4 & $\begin{array}{l}\text { Coleção que melhor apresentou trabalho com gêneros-apreciação }(+) \text { valor adequação } \\
\text { Muito bom - apreciação }(+) \text { valor } \\
\text { Grande variedade de gêneros. Traz questões atuais, integração de habilidades - } \\
\text { apreciação }(+) \text {, composição quantidade e complexidade - gradação }\end{array}$ \\
\hline & Prof 5 & $\begin{array}{l}\text { Aproximação da proposta - apreciação (+) valor } \\
\text { Grande diversidade de temas, várias sugestões - apreciação (+) composição } \\
\text { quantidade } \\
\text { Sinto falta de atividades orais em maior quantidade - apreciação }(-) \text { composição } \\
\text { quantidade. }\end{array}$ \\
\hline
\end{tabular}

Fonte: SILVA e PEREIRA (2014).

\section{O PROFESSOR, O LIVRO DIDÁTICO E OUTROS MATERIAIS DE ENSINO}

Não seria possível terminar esse texto sem considerar outros materiais de ensino além do livro didático de línguas. Esse é um elemento dentro do conjunto maior 
denominado "material didático", no qual podem estar contidos, também, CDs de áudio, DVDs, cartazes, cadernos de exercícios, gramáticas, revistas, manuais, mapas, gravuras, jogos, softwares, homepages e outros. Muitos desses outros materiais são disponibilizados pelas editoras que publicam livros didáticos para o público em geral, especialmente o livro didático de línguas. Algumas coleções de línguas estrangeiras, por exemplo, têm atrelados a elas materiais de vídeo, materiais diferenciados para trabalho com pronúncia, os chamados resource books (livros de recursos) com jogos, atividades extra, cartazes. Atualmente, as editoras de livros didáticos em geral disponibilizam, para professores e alunos adotantes de livros didáticos, sites específicos em que estão disponibilizadas tarefas, vídeos, infográficos, áudios, outras atividades e materiais que não poderiam estar no objeto impresso ou em sua versão em pdf, que muitas vezes configura o chamado "livro digital". Como atesta Paiva (2014, p. 346),

Algumas coleções didáticas já oferecem a versão digital e quem compra o livro recebe uma senha para ter acesso ao material digital. É comum também que as editoras publiquem em suas páginas eletrônicas, atividades digitais para os alunos ou atividades extras em formato pdf para serem copiadas pelos professores.

Apesar de atualmente esses materiais serem mais disponíveis, ainda não estão em sala de aula com o mesmo peso que está o livro didático. Os livros didáticos de línguas aprovados e distribuídos nas escolas públicas por meio do PNLD não têm outros recursos satélites (CHOPPIN, 2004), exceto o livro de línguas estrangeiras que é acompanhado apenas por um CD de áudio. Esse é um dos desafios para os produtores: a inserção no pacote do livro didático de diferentes mídias com intuito de promover letramentos digital e visual frente à restrição posta em edital (PAIVA, 2014). A solução encontrada até o momento é a disponibilização desse recurso para o professor e o aluno na Internet.

Mas a cultura escolar brasileira ainda é muito tradicional, e a rotina escolar raras vezes permite rupturas para que haja inserção de outros materiais didáticos no ensino. $\mathrm{O}$ professor tem horários reduzidos com cada turma, chegando a uma única aula por semana em várias instituições para o ensino de língua estrangeira, principalmente, e em aulas de língua materna têm sido cada vez mais fragmentadas na divisão entre conhecimentos linguísticos, produção de texto e literatura. Sistemas educacionais muitas vezes não dão ao docente e ao discente liberdade de criação (LEFFA, 2007), pois as avaliações ainda devem ser provas, e quase nunca são considerados outros instrumentos que poderiam ser produtivos no sentido de envolver o aluno também no processo de avaliação. Avaliações tradicionais espelhadas em exames nacionais (como o ENEM), como antigamente se fazia com os vestibulares, já acontecem em algumas escolas desde as primeiras séries do Ensino Fundamental, com foco em um treinamento para sucesso nesse exame. $\mathrm{Na}$ escola pública em geral, e também em instituições particulares, o professor ainda lida com turmas lotadas (com mais de 40 alunos), e as aulas duram somente 50 minutos, dificultando e muitas vezes impossibilitando trabalhos em laboratórios de informática, atividades fora de sala de aula envolvendo o uso da língua materna ou estrangeira, como por exemplo, comunicações via internet com alunos de outros contextos nacionais ou estrangeiros, promoção de campanhas educativas e publicitárias, criação de textos envolvendo vários 
modos de significação e comunicação - a multimodalidade (KRESS, 2010). O professor muitas vezes também não é usuário das novas tecnologias como os alunos são e, nesse caso, é preciso que ele também se veja como um aluno de seu aluno, que com ele também pode aprender a manejar alguns recursos de tecnologia digital. Por fim, merece destaque também as leis que proíbem a conversa em celulares em salas de aula e a interpretação de que o uso não é permitido, fazendo com que em muitas escolas haja normas proibindo alunos de levarem tablets e celulares para as aulas.

Tais fatos instigam a um pesquisador algumas perguntas: O que falta para que esses materiais sejam mais usados? Segurança para esse tipo de trabalho em que o aluno também assume o protagonismo de sua aprendizagem? Tempo para realização? Permissão por parte da instituição? Formação docente para promover autonomia ao docente, segurança? Pesquisas futuras sobre materiais didáticos poderão contribuir tocando nessas questões e em outras semelhantes.

Frente ao uso tão comum das tecnologias digitais no cotidiano em geral, é lamentável que a escola ainda não esteja preparada em termos de recursos e de visões mais abrangentes do ensinar e do aprender. Kress (2012) critica essa situação de maneira mais ampla, dizendo que não é mais permitido à escola desconsiderar novas formas de produção e de comunicação do conhecimento na formação do currículo. Para esse autor, ainda está fora de cogitação, nas escolas em geral, a construção de conhecimento à medida que problemas específicos dos estudantes são encarados, o que exige também outros princípios de avaliação e princípios epistemológicos novos. Em se tratando do contexto brasileiro, parece que isso se verifica na insistência de práticas tradicionais mesmo frente a livros didáticos novos e uma produção editorial didática de melhor qualidade já atestada por acadêmicos há algum tempo (por exemplo, ROJO, BATISTA E ZUÑIGA, 2005).

O professor de línguas, que segundo Bohn (2006) vive na contemporaneidade em constante aprendizagem, encontra-se ainda preso a parâmetros que não condizem com novas possibilidades de materiais e recursos didáticos. A sala de aula tradicional em fileiras, que simboliza menos interação, mais obediência e mais controle (PIMENTA, 2001), ainda não foi transformada, por exemplo, na sala de aula em forma de U, em que alunos possam se ver frente a frente, se expor. As salas ainda não dispõem, em sua totalidade, de um aparelho que existe em praticamente todas as casas: a televisão, que atualmente conta com tecnologias que permitem fazer dela diversos usos, podendo substituir equipamentos caros e frágeis como os projetores multimídia. $\mathrm{O}$ rádio e seus programas ainda não fazem parte das atividades didáticas das salas de aula ou de atividades de avaliação nas aulas de português e de línguas estrangeiras. Laboratórios de informática nas escolas ainda são usados muitas vezes como lugar para lazer, lugar de jogos, como momento de descanso para alunos e professores. A utilização de recursos tecnológicos como esses já é prevista nos Parâmetros Curriculares Nacionais do Ensino Fundamental publicados em 1998 (BRASIL, 1998), tanto para o ensino de língua portuguesa como de língua estrangeira. A pesquisa do Conselho Britânico sobre o ensino de inglês no Brasil atesta que o acesso a materiais didáticos é o grande desafio do ensino dessa língua em escolas públicas (BRITISH COUNCIL, 2015), o que nos motiva a perguntar: mesmo com 
o PNLD, com tantos livros didáticos sendo distribuídos, com as melhoras ocorridas na produção e na avaliação de obras, por que este é o desafio?

Enfim, a incorporação de tecnologias diversas como materiais ou recursos de ensino, novas maneiras de ensinar e a consideração de diferentes formas de aprender não são ainda comuns nas escolas. É preciso mudar a cultura escolar, tão arraigada em limites de espaço e tempo, provas, autoridade do docente, submissão do discente, material impresso apenas, que serve muito bem ao status quo estabelecido, numa educação mais opressora que atende a uma classe dominadora ao invés de promover integração, empoderamento, e libertação, no sentido freireano (FREIRE, 2010).

Mesmo em meio a tantos avanços de materiais didáticos, frente às mudanças nos livros didáticos e com tantas políticas públicas, a escola ainda é a instituição tradicional que prefere a conformação como maneira de formar cidadãos. Conforme mostra Marcelo (2010), as reformas educacionais, e podem ser incluídas aí as novidades trazidas por um programa como o PNLD e as mudanças em livros didáticos dele decorrentes, não são suficientes para trazer aos professores de línguas segurança e autonomia para o descentramento de seu papel nos processos de ensinar e de aprender.

\section{CONCLUINDO}

A relação professor-livro didático parece ter ainda longa duração. Esse material didático faz parte do exercício da profissão docente e, mesmo quando se diz que não é usado, é por ele e pela maneira com que ele organiza o conhecimento que os professores se organizam, ou se espelham.

O professor precisa do livro didático como aliado uma vez que enfrenta as condições mais adversas para desenvolvimento de seu trabalho. Livros de boa qualidade, que incorporem atividades e novas maneiras de ensinar e de aprender são necessários, mas também é preciso espaço, tempo e mudanças na rotina escolar para que outros materiais didáticos (muitas vezes previstos pelo autor do livro didático) também se façam presentes nas salas de aula de línguas.

Nesse sentido, o PNLD é avanço como política pública, que se transformou ao longo do tempo numa política de Estado. Aperfeiçoamentos e ampliação dessa política têm provocado mudanças na produção editorial brasileira de didáticos (ROJO, BATISTA E ZUÑIGA, 2005), também têm permitido que visões mais recentes de ensino e de aprendizagem sejam apresentadas aos docentes e discentes - promovendo, assim, formação continuada de docentes, e ainda têm democratizado o acesso a um material didático de qualidade. Ao se propor dar voz ao professor no momento de escolha de livros, o PNLD também se faz como promotor de uma participação docente mais democrática.

Mas, é necessário que outras políticas públicas de provimento de materiais didáticos promovam isso, ampliando o acesso a computadores, às conexões de rede, aos recursos móveis, a materiais paradidáticos e de leitura literária. O PNLD e outros programas de mesma natureza também precisam ultrapassar questões logísticas e financeiras, fomentando uma política de maior abrangência e de verdadeiro apoio ao 
docente, promovendo formações continuadas, visando conscientização do papel do livro didático e de outros materiais e recursos, focando desafios, o papel político do professor e mostrando que ele não é o robô controlado por um livro adotado.

Por fim, a escola, enquanto instituição, precisa sofrer mudanças no sentido de que docentes sejam receptores competentes e conscientes do livro didático, motivados e não idealizados. E são essas as pessoas que fariam essa mudança, pessoas de dentro da escola, construtores da realidade em que atuam.

\section{REFERÊNCIAS BIBLIOGRÁFICAS:}

BOHN, I. H. Maneiras inovadoras de ensinar e aprender a necessidade de des(re)construção de conceitos. In: LEFFA, J. V. O Professor de Linguas: Construindo a profissão. 2.ed. Pelotas: EDUCAT, 2006. p. 123-131.

BRASIL. Parâmetros Curriculares Nacionais - Linguas Estrangeiras Modernas. Brasília: MEC / SEB, 1998.

BRASIL. Parâmetros Curriculares Nacionais - Lingua Portuguesa. Brasília: MEC / SEB, 1998.

BRASIL. Resolução 42 de 28 de agosto de 2012 (Alterada pelas Resoluções no 22, de 7 de junho de 2013, e n n $^{4} 44$ de 13 de novembro de 2013). Brasília: Congresso Nacional, 2012.

BRASIL. Guia do Livro Didático 2015 - Línguas Estrangeiras Modernas Inglês e Espanhol. Brasília: MEC / SEB, 2014.

BRITISH COUNCIL. O Ensino de Inglês na Educação Pública Brasileira - Elaborado com exclusividade para o British Council pelo Instituto de Pesquisas Plano CDE. $1^{\mathrm{a}} \mathrm{ed}$. São Paulo: British Council, 2015

CASSIANO, C. C. F. O mercado do livro didático no Brasil do século XXI: a entrada do capital espanhol na Educação Nacional. São Paulo: Editora UNESP, 2013.

CELANI, M. A. A. Ensino de Línguas Estrangeiras: Ocupação ou profissão. In: LEFFA, J. V. O Professor de Linguas: Construindo a profissão. 2.ed. Pelotas: EDUCAT, 2006. p. 23-43.

CITELLI, A. (org.) Educomunicação: imagens do professor na mídia. São Paulo: Ed. Paulinas, 2012.

CHOPPIN, A. História dos livros e das edições didáticas: sobre o estado da arte. Educação e Pesquisa, São Paulo, v.30, n.3, set./dez. 2004, p. 549-566. 
CORACINI, M. J. O livro didático nos discursos da Linguística Aplicada e da sala de aula. In: CORACINI, M. J. (Org.). Interpretação, autoria e legitimação do livro didático. Campinas: Pontes, 1999. p. 17- 26.

FREIRE, P. Educação como Prática de Liberdade. $33^{\text {a }}$ reimpressão. Rio de Janeiro: Paz e Terra, 2010.

JODELET, D. Répresentation sociale: phénomènes, concept et théorie. In.: MOSCOVICI, S. (ed.) Psychologie Sociale. 5 ed. Paris: PUF Fondamental, Presses Universitaires de France, 1995, p. 357-378.

KRESS. G. Multimodality: a social semiotic approach to contemporary communication. New York, London: Routledge, 2010.

KRESS. G. O ensino na era da informação: entre a instabilidade e a integração. In.: LEITE GARCIA, R. ; MOREIRA, A. F. B. Curriculo na Contemporaneidade - Incertezas e Desafios. 4ed. São Paulo: Cortez Editora, 2012, p. 127-152.

LEFFA, V. Aspectos políticos da formação do professor de línguas estrangeiras. In.: LEFFA, V. (org.) O Professor de Linguas: Construindo a Profissão. 2 ed. Pelotas: EDUCAT, 2006, pp 353-376.

LEFFA, Vilson J. Pra que estudar inglês, profe?: Auto-exclusão em língua-estrangeira. In.: Claritas, São Paulo, v. 13, n. 1, , maio 2007, p. 47-65

MARCELO, C. O professor iniciante, a prática pedagógica e o sentido da experiência. Revista Brasileira de Pesquisa sobre Formação Docente. Volume 02, número 3. Editora Autêntica (coord.), ago/ dez de 2010, p.11-49.

Disponível em http://formacaodocente.autenticaeditora.com.br/artigo/exibir/8/18/1. Acesso em 26/01/2016

MOSCOVICI, S. Representações Sociais: Investigações em Representações Sociais. 4 ed. Petrópolis: Vozes, 2003.

OLIVEIRA, P. R. Processo de escolha do livro didático de História numa perspectiva discursiva. Dissertação (Mestrado em Estudos de Linguagens) - Centro Federal de Educação Tecnológica de Minas Gerais, Belo Horizonte, 2015.

PAIVA, V. L. M. O. Os desafios na produção de materiais didáticos para ensino de línguas no ensino básico. Revista (Con)Textos Linguísticos, Vitória, v.8, n. 10.1, 2014, p. 344-357. 
PIMENTA, S. M. O. A Semiótica Social e a Semiótica do Discurso de Kress. In.: MAGALHÃES, C. (org.) Reflexões sobre a Análise Crítica do Discurso. Belo Horizonte: Faculdade de Letras / POSLIN/ UFMG, 2001, pp.185-206.

ROJO, R.; BATISTA, A. A. G.; ZUÑIGA, N. C. Produzindo livros didáticos em tempo de mudança (1999-2002). In.: COSTA VAL, M. G.; MARCUSCHI, B. (org.) Livros Didáticos de Lingua Portuguesa: letramento e cidadania. Belo Horizonte: CEALE, Ed Autêntica, 2005, p. 47-72.

SILVA, R. C. Representações do livro didático de inglês: análise dos discursos de produtores e usuários com base na Linguística Sistêmico-Funcional. Tese de Doutorado. Rio de Janeiro: Departamento de Letras PUC-Rio, 2012.

Livro Didático de Inglês: que livro é este? Discursos de produtores e usuários. 1. ed. Curitiba:

Appris, 2016.

; PEREIRA, M. L. P. de O. A.

A avaliação por professores dos livros didáticos do

PNLD adotados em contexto de Ensino Médio. Comunicação apresentada no 41st

International Systemic-Functional Linguistics Congress; X Congresso ALSFAL.

Universdad Nacional de Cuyo, Mendoza, Argentina, 2014.

SCHEYERL, D. e SIQUEIRA, S. Entrevista com Maria Luíza Ortiz Alvarez. In.: SCHEYERL, D. e SIQUEIRA, S. (org.) Materiais Didáticos para o ensino de línguas na contemporaneidade: contestações e proposições. Salvador: EDUFBA, 2013, p. 497-522. SOUZA, D. M.

Gestos de Censura. CORACINI, M. J. (Org.). Interpretação, autoria e legitimação do livro didático. Campinas: Pontes, 1999, p. 57-64.

TEIXEIRA, R. F. B. As relações professor e livro didático de alfabetização. Anais do VIII Congresso Nacional de Educação EDUCERE. Curitiba, PR: PUC-PR, 2008, PP.772-811. Disponível em http://www.pucpr.br/eventos/educere/educere2008/anais/pdf/772_811.pdf. Acesso em 22/05/2016.

ZAMBON, L. B.; TERRAZAN, E. A. Políticas de material didático no Brasil: organização dos processos de escolha de livros didáticos em escolas públicas de educação básica. Revista Brasileira de Estudos Pedagógicos (online), Brasília: INEP / MEC, v. 94, n. 237, maio/ago. 2013, p. 585-602. 
Recebido em: 05/06/2017

Aprovado em: 23/07/2017

Publicado em: 01/02/2018 